\title{
Editorial: Technical Creatives - Teaching Computer Games
}

\author{
Written by Jim Scullion \\ School of Computing, University of the West of Scotland, Ayr Campus, Ayshire, United Kingdom KA8 0SX
}

This special edition of The Computer Games Journal contains dissertations and essays by undergraduate computer games students of the University of the West of Scotland (UWS). As one of the academics who has the challenge and privilege of teaching these students, I'm pleased to have been invited to write this editorial. If you'll bear with me I'll provide a very brief bio to give some context to what follows. I had a fairly successful career in corporate computing, starting as a business analyst and reaching board level before succumbing to the siren call of education. My first teaching experience was in the area of multimedia computing before I switched to the emergent field of computer games. I have a confession to make: my first degree was in Humanities. Because I have gained my computing qualifications and experience after that initial degree, I think that my perspective can encompass both sides of the apparent dichotomy I'm about to discuss.

As part of my role within the UWS, I am responsible for a module called Computer Games Design. This is, to me at least, an interesting and challenging module for students on our computing programmes. It's challenging in one sense because it requires the students to tap into their own creativity to develop a game concept that optimises the gestalt of the player's experience. They have to design the game environment, characters, artefacts, narrative, music, sound effects, user interface and gameplay. It requires a combination of aesthetic, logical and inter-personal skills. A few struggle to rise to the challenge but the large majority revel in discovering their own latent talents and creativity. Pass rates are very high, and student feedback is overwhelmingly positive. Every year I am sincerely impressed by the hard work and dedication of the students.

But...there has to be a 'but', doesn't there? Some of my colleagues in the School of Computing are dismissive of the module, describing it with an implied sneer as 'non-technical'. For some people that's the ultimate insult. At the same time I'm hearing some computing students describe some of the 'technical' modules they undertake in the most disparaging terms. For some of these modules pass rates are far below university norms, and many students indicate that they have not had an engaging or positive learning experience.

I recently had very fruitful discussions with colleagues in the School of Creative and Cultural Industries about their students on the Digital Arts programme taking the Computer Games Design module. It doesn't sound very revolutionary as a concept, but there were some serious concerns raised - mostly concerning whether the content of the module would be 'too technical' for digital arts students. I had to give reassurances about this. During these discussions I was interested in my colleagues' use of the term 'creative'. They clearly feel that it is valid to describe themselves and their students as 'creatives' with a clear implication that 'creatives' have no capacity for tackling 'technical' subjects. And where did the term 'Creative Industries' come from? I'm not aware of any industry sector that doesn't have to be creative in one way or another.

In my view both sides of this dichotomy are underestimating the capacity and potential of our students. In fact, I would suggest that it's not a true dichotomy at all, just the lazy application of meaningless labels. All of our students come to us with an enormous potential for absorbing and assimilating technical information. The information may relate to the use of hardware, software, paintbrushes, musical instruments, words, concepts or the human body. It's all technical, just a different kind of technical. And we are all creative.

An associated issue is the decline in the numbers of UK students taking computing-related subjects at secondary and tertiary level at a time when there is a high level of unfilled vacancies for professionals with these qualifications, and the only sectors with actual or potential growth at this time of recession are those that require these skills. The view is that the roots of this issue lie in the schools, where computing per se has been gradually replaced by the teaching of basic ICT literacy because of the difficulty in recruiting teachers with the required qualifications. I have personal knowledge of secondary schools where computing is taught by staff whose qualifications are for teaching other unrelated subjects. Not surprisingly, many secondary students are bored and turned off by this experience, so they have no interest in studying computing at tertiary level. This, of course, has created what seemed to be a terminal downward spiral: not enough Computing teachers; remove 
the computing-specific parts of the curriculum; fewer computing students at tertiary level; fewer computing graduates; hence fewer computing teachers.

Recently the UK Government announced an initiative to improve this situation, including the payment of a 'golden hello' of $£ 20,000$ to properly qualified computing graduates who wish to become teachers, and a complete review of the school curriculum for Computing (BBC News, 2012). The aim is to return the subject to a state where it is seen by students as interesting, relevant and valuable. This in turn should stimulate interest in studying the subject at tertiary level. Unfortunately this initiative will not include Scotland. Although by any measure the situation is just as bad in Scotland, the response from the Scottish Qualifications Authority has so far been one of staggering complacency. It is to be hoped that this will not persist.

I would contend that computer games, with its combination of cognate challenges and potential for engaging learners, is the ideal vehicle for such a renaissance of Computing as a subject in schools. I can, however, foresee some problems in the adoption of a scheme of this nature. As part of my research I recently undertook a survey of the game-playing behaviour of all UWS students (Scullion et al, 2011). Among many other things, the findings showed a clear difference between curricular areas in terms of the time spent playing computer games. Students in the School of Computing play games most, closely followed by the School of Engineering. At the bottom of the table are students from the School of Education. These students, of course, are our future school teachers. My concern would be that this apparent lack of interest in playing computer games will be translated into a lack of interest in teaching computer games.

I hope that at least some of them have the opportunity to read the contents of this special edition, which stand as testimony to the high quality work of which computer games students are capable.

\section{References}

BBC News. Computer science teachers offered cash incentive. [Online]. Available at: http://www.bbc.co.uk/news/education20003327 [Accessed: 5 November 2012].

Scullion, J., Stansfield, M. and Connolly, T. (2011). A Survey of Students' Improved Mastery of Game Playing Skills Through Informal Online Game-Based Learning. In: Proceedings of the 5th European Conference on Games Based Learning, 20 October 2011, Athens: Academic Publishing Limited, p.535-542. 